INVESTIGACIÓN/RESEARCH

\title{
LA BURBUJA INMOBILIARIA VISTA DESDE LA PUBLICIDAD. PROPUESTA PARA EL ESTUDIO DE LA PUBLICIDAD DEL MERCADO DE LA VIVIENDA (1997-2006)
}

Antonio Raúl Fernández Rincón': Universidad de Murcia (España). antonioraul.fernandez@um.es

\section{RESUMEN}

Mediante el presente artículo queremos hacer público nuestro proyecto de investigación acerca de los mecanismos discursivos de la publicidad inmobiliaria en España durante el período 1997-2006, época coincidente con la llamada burbuja inmobiliaria o "boom" del ladrillo. La publicidad inmobiliaria, a pesar de referirse a un sector tan relevante para el devenir económico, político y social de las sociedades industrializadas como es el de la vivienda, creemos que no ha sido objeto de estudio en la medida de su trascendencia. Nuestro interés en este momento reside en dos aspectos; confirmar la pertinencia de un estudio así y exponer nuestro planteamiento de estudio del discurso publicitario con el fin de generar conclusiones e inferir características y peculiaridades de la burbuja inmobiliaria en España

PALABRAS CLAVE: Publicidad inmobiliaria - España - burbuja inmobiliaria - crisis.

\footnotetext{
1Antonio Raúl Fernández Rincón: Profesor asociado de la Facultad de Comunicación y Documentación de la Universidad de Murcia.

Correo: antonioraul.fernandez@um.es
} 


\title{
ADVERTISING \& REAL ESTATE BUBBLE PROPOSAL FOR THE STUDY OF ADVERTISING HOUSING MARKET (1997-2006)
}

\begin{abstract}
Through this article we want to publish our research project on the discursive mechanisms of advertising real estate in Spain during the period 1997-2006, a period coinciding with the so-called real estate bubble or "boom" of the brick. The real estate advertising, despite referring to an industry as important to the future economic, political and social industrialized societies such as housing, we believe it has not been studied to the extent of its significance. Our interest now lies in two aspects; confirm the relevance of such a study and present our approach to study the discourse of advertising to generate conclusions and infer characteristics and peculiarities of the real estate bubble in Spain.
\end{abstract}

KEY WORDS: Real Estate advertising - Spain - real estate bubble - crisis.

\section{INTRODUCCIÓN}

La publicidad de productos y servicios inmobiliarios es una actividad de escaso protagonismo y relevancia en el sector que nunca pareció configurar una categoría reconocida dentro de la propia disciplina publicitaria. Bien sea por la escasa repercusión de sus mensajes o por la supuesta falta de creatividad en sus propuestas, dicha actividad ha quedado tradicionalmente relegada a un segundo plano. Arrinconada a veces en abigarradas secciones de la prensa escrita o limitada a publicaciones sectoriales, quizá hayamos prestado menor atención de la que se merece a una actividad que ha movido y mueve grandes cantidades de dinero y materia gris.

Tras un primer acercamiento al conocimiento de la publicidad inmobiliaria y sus mecanismos en las principales fuentes académicas, bibliotecas universitarias y generales, archivos bibliográficos, publicaciones científicas y registros de tesis doctorales a nivel mundial, nos encontramos con una escasa producción académica, por no decir inexistente. Los únicos antecedentes localizados hasta la fecha los hallamos en Brasil, un país que en estos momentos se encuentra inmerso en una etapa de crecimiento económico y estructural y que por lo tanto constituye un terreno abonado para el desarrollo de una incipiente industria inmobiliaria. Se trata de la tesis doctoral de (Alves Dias, 2009) y los artículos de (Hélio Junqueira, 2009) y (Renno, 2009).

Existe además cierta confusión terminológica con respecto a la publicidad registral inmobiliaria o publicidad legal, como aquel procedimiento de carácter meramente informativo que se integra en el derecho hipotecario. Sobre este aspecto sí hay una producción bibliográfica relevante. En España contamos con la tesis doctoral: La publicidad inmobiliaria en el derecho hipotecario histórico español, (Serna 
Vallejo,1995).

La publicidad inmobiliaria, por tanto, sería un instrumento informativo cuyo objetivo se centra en la eliminación de incertidumbres en torno al valor y estado de los bienes inmuebles de cara a los sucesivos adquirentes de los mismos, como bien define Martínez Valencoso, "Precisamente por satisfacer esa necesidad de certidumbre, las normas legales elaboran instrumentos de publicidad. Un sistema de publicidad previene la celebración de acuerdos fraudulentos". (Martínez Valencoso, 2008, p. 10). Las referencias a este tipo de publicidad no aluden al propio discurso publicitario, estaríamos ante una acepción del término que se refiere al conjunto de medios empleados para difundir una información e incluso, como es este caso, aportar seguridad jurídica.

A partir de este momento, empezamos a vislumbrar la posibilidad de desarrollar un trabajo que aborde la publicidad inmobiliaria en su acepción quizá menos reconocida. Un estudio que delimite un espacio conceptual propio para la publicidad inmobiliaria como discurso persuasivo, incluso por qué no, dotándola de una denominación más acorde con sus peculiaridades y que convierta por primera vez en categoría, un área de la publicidad comercial de gran trascendencia como es la publicidad de productos y servicios relacionados con la vivienda. Hoy más que nunca parece evidente el peso del sector inmobiliario en el devenir de las sociedades industrializadas. Sin ir más lejos, el inmobiliario suele ser señalado como el uno de los sectores que más ha contribuido en la crisis económica que actualmente viven los países industrializados. George Soros, el legendario inversor y filántropo, habla precisamente en este sentido al tratar de explicar la crisis económica actual.

Desde 2000 hasta mediados de 2005, el valor del mercado de las viviendas construidas subió más del 50\% y hubo un boom de nuevas construcciones. Merril Lynch observaba que aproximadamente la mitad de todo el crecimiento del PNB estadounidense en la primera mitad de 2005 estaba relacionado con las viviendas: o bien directamente, a través de la construcción de casas y bienes relacionados con las casas como nuevo mobiliario, o indirectamente, a través de la mayor demanda creada por el dinero generado gracias a la refinanciación de las hipotecas. (Soros, 2008, p. 18)

Las voces que culpan al sector inmobiliario como generador de la crisis económica que asola a los países industrializados desde finales de la primera década de 2000, se encuentran con las teorías que amplían el foco del problema para culpar al propio sistema económico y financiero, cuyo desarrollo exponencial y por qué no decirlo, creatividad en sus métodos de trabajo y en sus productos, han generado un entramado de relaciones globales que escapa incluso de la intervención gubernamental. (Roubini y Mihn, 2010) se refieren a este aspecto de un modo metafórico al compararlo con la tectónica de placas. Para los autores, la crisis, al igual que los terremotos no responde a una causa única, sino que es producto de tensiones y presiones acumuladas a los largo de los años. "La titularización de préstamos basura no fue más que el principio; también desempeñaron un papel los cambios en el gobierno corporativo y los sistemas de bonificaciones (...) las hipotecas tóxicas no fueron sino la señal más evidente de una putrefacción profunda y sistémica" (Roubini y Mihn, 2010, p. 106). 
Otros aspectos influyentes que a menudo son relacionados con el desencadenamiento de la crisis económica actual se sitúan en torno a la incesante desregularización, fruto en la mayoría de ocasiones de un ímpetu gubernamental por implantar medidas liberales que animasen el consumo, reactivasen la economía y diesen un empujón definitivo al mercado de libre competencia. En esta línea se señala de igual forma el papel de las agencias de calificación y las grandes corporaciones too big to fail, cuyos tentáculos abrazan grandes áreas de poder en un contexto mundial globalizado.

España constituye un ejemplo paradigmático de repercusión e impacto de todo aquello relacionado con la promoción inmobiliaria. Este país ha encabezado durante años los rankings de construcción de viviendas y son muchas las voces que demuestran el feroz impacto que ha tenido este hecho en el desarrollo económico, social y político a lo largo de las últimas décadas. Estaríamos ante un factor desencadenante de la especial virulencia con que la crisis económica mundial viene afectando al país.

Hoy en día, parece asumido que en España se produjo una burbuja inmobiliaria durante los últimos años de la década de los noventa y cuyo final aún no resuelto, coincide con el inicio de la crisis financiera internacional, en torno al período 20062007. En este punto, si el sector inmobiliario tiene tanto peso específico como para provocar una deriva económica y financiera tan catastrófica como la que vivimos hoy en día ¿Tiene sentido que no exista una mayor investigación relativa al tema desde el punto de vista del discurso publicitario?.

Partiendo de un evidente déficit de investigación en el ámbito de la publicidad inmobiliaria -en su acepción de comunicación persuasiva-, explicamos el desarrollo de la investigación que nos proponemos afrontar en este sentido, no sin antes demostrar la legitimidad de la investigación en publicidad para describir fenómenos sociales, políticos, económicos y culturales, como es el caso de la burbuja inmobiliaria.

\section{OBJETIVOS}

En base a este supuesto establecemos una serie de objetivos generales y específicos que van desde la intención de conocer las localizaciones territoriales que han generado el grueso de la producción publicitaria, hasta conocer la propia tipología de mensajes publicitarios realizados y los medios de comunicación más usualmente empleados. A nivel específico, nos proponemos conocer los diferentes mecanismos discursivos de la publicidad inmobiliaria y analizar su relevancia y contribución a la consolidación de la década prodigiosa del sector inmobiliario en España.

Si por una parte parece pertinente el estudio de la publicidad inmobiliaria a través de un marco metodológico específico, debido a la inexistencia hasta hoy de un trabajo así, de igual forma, cualquier conocimiento acerca de un fenómeno que parece haber causado grandes estragos en la economía de determinados países sería bienvenido, ya que ayudaría a dilucidar situaciones conflictivas y decisiones erróneas en el futuro.

Sabemos que la industria publicitaria se ha convertido en una enérgica herramienta de 
transmisión de valores, (Hellín Ortuño, 2007) o su estrecha relación con los social, (Codeluppi, 2007), el estudio de la publicidad inmobiliaria puede arrojar conclusiones certeras sobre el contexto en el que actúa. De esta forma planteamos la hipótesis sobre la que se desarrollará nuestro estudio en los siguientes términos; a partir del estudio de la publicidad inmobiliaria en España, durante el período 1997-2006, podemos inferir características y peculiaridades de lo que vino a llamarse "burbuja inmobiliaria o boom del ladrillo.

\section{METODOLOGÍA}

Decidimos realizar una investigación; exploratoria y descriptiva. Exploratoria, porque como dijimos anteriormente, estamos ante un fenómeno poco estudiado. Para refrendar esta afirmación, es necesario volver a recordar que no estamos ante un estudio de la publicidad inmobiliaria desde al ámbito jurídico, entendemos y delimitamos aquí la publicidad inmobiliaria como el conjunto de técnicas y recursos utilizados para la promoción y venta de productos inmobiliarios. En este sentido, realizaremos una exploración de los productos comunicativos más relevantes, durante la época estudiada. La selección de estos materiales, se llevará a cabo siguiendo unos criterios previamente establecidos. Lógicamente, ante la imposibilidad de recabar todos los materiales producidos, se establecerá una metodología de recogida de documentación que asegure la correcta interpretación y la posibilidad de extrapolación de datos. De este modo, se establecerán categorías relevantes que, ahora sí, posean la capacidad de representar a la totalidad. A través de esta selección de documentación perseguimos el objetivo de clarificar y exponer de la manera más representativa el panorama estudiado, tanto en sentido geográfico conceptual, tipos de soportes, etc.

De igual forma, hablamos de un enfoque descriptivo porque como aludimos en la expresión de los objetivos, queremos especificar las propiedades de los mensajes, describir los discursos empleados, los conceptos, la ubicación, la intención, los medios usados y las posibles repercusiones.

La elección de España como contexto en el que se desarrolla el análisis no ha sido arbitraria, la cercanía del entorno a los propios investigadores y el propio hecho de haberlo vivido en primera persona, facilitará la búsqueda y recogida de información. Pero este no es el motivo esencial de la elección, no cabe duda de que España es uno de los países industrializados en los que mayor incidencia ha tenido el llamado boom del ladrillo, junto con Irlanda en el ámbito europeo y Estados Unidos, vienen siendo señalados como los tres principales focos de atención en este sentido. Esta afirmación es compartida no sólo por la producción literaria, periodística y académica en torno al tema, sino por todas aquellas referencias que aún hoy en 2012 siguen apareciendo para comprender y analizar el impacto de la crisis económica mundial.

El carácter de una investigación de este tipo debe ser meramente internacional y así lo hemos entendido desde el principio, las referencias al objeto de estudio, tanto del ámbito publicitario como del inmobiliario vienen siendo recuperadas desde numerosos puntos a nivel mundial. La delimitación que hemos marcado se refiere, por tanto, al trabajo de análisis. En este sentido debemos recordar que, motivados por 
la producción académica en torno a nuestro objeto de estudio por parte de autores de origen brasileño, y conscientes de la posibilidad de ampliar nuestro punto de visión y análisis más allá del territorio español, hemos considerado oportuno establecer una serie de vínculos con aquel país. Estos vínculos de nuestra investigación con el caso brasileño sin duda se han visto alimentados de la intuición por ambas partes de que los resultados pudieran ser extrapolables ya que el país se encuentra en una situación económica, política y social muy similar a la que vivió España al inicio de los 90. El estudio puede ser más ambicioso y podrían extraerse paralelismos y conclusiones interesantes para ambas partes.

La estructura de la investigación consta de cuatro grandes bloques; un primer bloque en el que desarrollamos nuestra fundamentación teórica en base al estudio de la investigación en publicidad y un marco teórico centrado principalmente en el conocimiento de las pautas que rigen el mercado de la vivienda en sentido amplio. Hablamos en este punto de analizar el concepto de ideología en el ámbito de la vivienda y valorar en su justa medida el carácter económico de la actividad inmobiliaria. A continuación establecemos las bases teóricas sobre las que pivotará nuestro estudio, las interconexiones con otras disciplinas de las ciencias sociales como pueden ser; la antropología, la sociología o la psicología social.

El segundo bloque de la investigación se centra esencialmente en la disciplina publicitaria y en el contexto. Consta de cinco áreas, nuestra intención aquí es conocer el contexto social de la publicidad, explorar la dinámica del consumo en las sociedades industrializadas y analizar el discurso publicitario en la posmodernidad. Por último creemos necesario ofrecer una perspectiva general del panorama social, económico y político durante el periodo de estudio, con el fin de establecer un marco contextual concreto que hable de aspectos relacionados con el devenir político, económico y social principalmente.

El tercer paso de la investigación aquí propuesta lo constituye el propio análisis. A través de un método de análisis creado ex profeso y partiendo de las aportaciones del modelo sociosemiótico de la comunicación (Rodrigo Alsina, 1989), analizaremos una cantidad significativa de mensajes publicitarios aparecidos en prensa nacional durante el período 1997-2006 y brasileña durante los años 2010-2012. El principio racional que da coherencia al modelo sociosemiótico, es de matriz fenomenológica. "Así el principio racional que sustenta el modelo sociosemiótico de la comunicación de masas es la concepción de la construcción social de la realidad como un proceso de producción, de circulación y de consumo discursivo". (Rodrigo Alsina, 1989, p. 150). Para el autor, este modelo se encuentra más próximo a la sociosemiótica pluridisciplinar de (Verón, 1987), donde la primera condición para el análisis del discurso es su puesta en relación con unas determinadas condiciones en las que fue generado, que a una perspectiva de carácter inmanentista; centrada en el análisis del discurso en sí mismo.

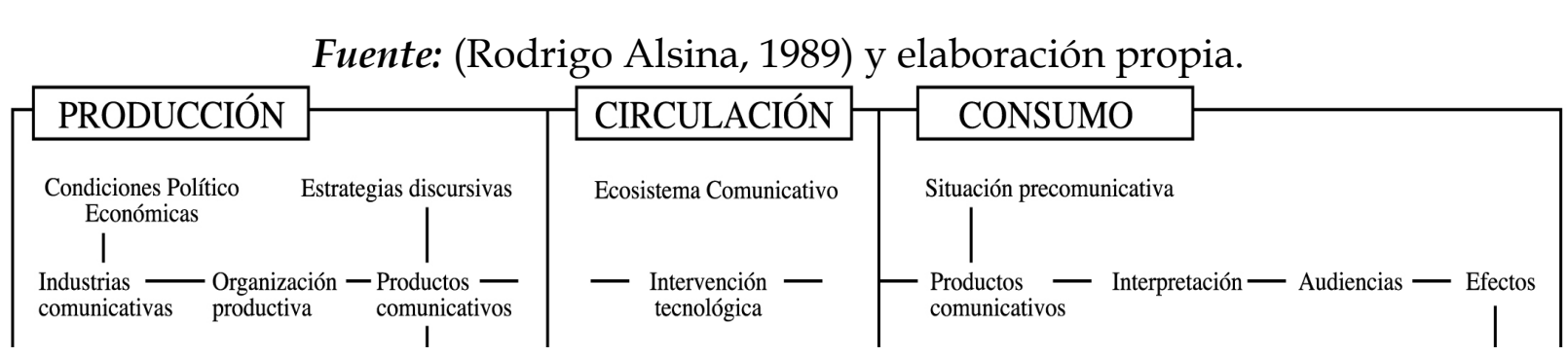


Según este modelo, la comunicación sería un proceso que consta de tres fases: producción, circulación y consumo. Las condiciones determinan pues, unas industrias comunicativas y a su vez, una organización productiva que elabora unos productos comunicativos específicos. Dicho de otro modo, no es posible una concepción de la comunicación social sin tener en cuenta una realidad social.

En el caso que ocupa esta investigación parece obvio que este determinismo es clave para entender los productos comunicativos que se generaron.

Hay que analizar, por tanto las características políticas, económicas y culturales que incidieron en las industrias comunicativas y por extensión en la producción de los discursos. En lo que respecta a las industrias comunicativas no debe pasarse por alto la influencia de los grupos de presión y los centros de decisión. En el ámbito de la circulación de igual forma, debemos contemplar y concretar el llamado ecosistema comunicativo de los medios, el macro discurso, la globalidad discursiva y las interrelaciones que se producen entre diferentes discursos, la incidencia de la tecnología en el significado de estos y en su consumo.

Por último, el análisis debe centrarse en el consumo del discurso. En este sentido es primordial conocer y reconocer al destinatario, su biografía, en contexto en el que se mueve, las circunstancias específicas que motivan el consumo, en definitiva, cómo es vivida por el individuo y los grupos sociales la realidad propuesta por los medios.

Llegaríamos por tanto a la fase de resultados en base a la cual estaríamos en disposición de ofrecer, mediante las oportunas normas de interpretación publicitaria, las características y peculiaridades del "boom" inmobiliario español y los posibles paralelismos que puedan darse con el caso de Brasil.

\section{RESULTADOS}

El hecho de considerar de especial relevancia la correcta contextualización de la presente investigación, nos motiva a profundizar en toda aquella bibliografía y hemerografía que de algún modo nos ayude a situar la investigación en un contexto político, económico y social perfectamente definido. El mercado inmobiliario no es un fenómeno aislado, muy al contrario, sabemos de su interdependencia con el contexto en el que se desarrolla. La política inmobiliaria de estos años, la legislación, las medidas favorecedoras o correctoras, deben mostrar su grado de implicación. La fisonomía de una sociedad en un momento determinado, las perspectivas económicas, las cifras macro y micro económicas, los movimientos sociales y culturales, el tránsito de población, todo ello debe estar presente con el fin de hacernos una composición de lugar más acertada y poder trabajar en torno a los objetivos propuestos de una manera más centrada y certera.

Son varias las razones que avalan el hecho de acometer una investigación como la que proyectamos aquí, algunas de ellas ya están aludidas más arriba. La relevancia de la temática, como ya hemos aludido anteriormente, provoca que la discusión sobre 
nuestro objeto de estudio sea afrontada desde una perspectiva multidisciplinar. Creemos que el reduccionismo de centrar nuestra mirada en un solo tipo de variables; económicas, culturales o sociales, no respondería con veracidad a la importancia del objeto estudiado. En este sentido, para verificar la pertinencia de dicho estudio, centramos la discusión sobre los siguientes puntos:

- España como ejemplo paradigmático a nivel mundial de la evolución y éxtasis del sector inmobiliario durante las últimas décadas

- La deriva del sistema capitalista, las características esenciales del consumo y su influencia en el mercado de bienes y servicios inmobiliarios

- Arquitectura, urbanismo, la ciudad posmoderna, sociología política, economía

- Las industrias de la comunicación, la publicidad, el análisis de los discursos, las aportaciones de la semiótica. Posmodernidad, ideología, medios de comunicación y poder

El análisis de las claves que conforman a España como un país de referencia con respecto al mercado inmobiliario y la formación de la burbuja no puede escapar de la contemplación de los grandes hitos de la historia reciente del país. Entre las circunstancias más importantes que concurren en el país a lo largo de los últimos años del siglo XX y que como veremos, está relacionada en buena medida con nuestro objeto de estudio, podemos situar la internacionalización del país o su definitiva presencia en el panorama internacional, ahora si, con voz y voto.

Las entidades supranacionales hoy, dan sentido a gran parte de las actuaciones y el devenir de los estados industrializados, entre ellos España, como miembro de pleno derecho. Durante la década de los 90 se produjo una importante expansión del sector privado en España, conformando un importante conglomerado de grandes empresas con una importante presencia internacional; Telefónica, Repsol, Argentaria, Tabacalera, Endesa, Aceralia, Gas Natural, Aldeasa y otras. Esta expansión y crecimiento fue provocado en buena medida la oleada de privatizaciones que se pusieron en marcha para reducir la deuda pública. “Una desamortización que superó en valor los cuatro billones de pesetas entre 1996 y 1999". (Tusell, 2002, p. 183).

A nivel público o más bien, a nivel país, el acontecimiento más relevante de esta época es la presencia del España en la Unión Europea. Aunque la firma del tratado de adhesión a las Comunidades Europeas por parte del estado español, data del 1 de enero de 1986, fecha en la que se convierte en miembro de pleno derecho de la llamada por entonces Comunidad Económica Europea (CEE).

Las consecuencias de dicha inmersión, son especialmente relevantes a partir de la década de los noventa. La adhesión supuso el escalón definitivo para la inclusión de España en el escenario internacional como potencia de tamaño medio. Los cambios económicos y sociales producidos a raíz de la incorporación a la UE son de gran calado. Este hito histórico, no solo supone la oportunidad definitiva para un país que compartía el deseo común de salir de su aislamiento secular y conseguir la estabilidad democrática y modernización general, ansiada desde hace largos años.

La entrada en la UE generó una mayor apertura económica y una mayor competitividad a todos los niveles, gracias entre otras cosas a la unión aduanera, la 
consolidación del mercado común europeo y más tarde la unión monetaria y económica. Así lo demostraba el estudio publicado en 2006 por el Real Instituto Elcano donde se califica de extraordinario el balance económico, político y social de los primeros 20 años de integración de España en la Unión Europea.

Hace 20 años, la inflación española se acercaba al 10\% anual, la tasa de paro superaba el $17 \%$ y el PIB estaba en el $71 \%$ de la media comunitaria. Hoy la inflación está en el $3 \%$, el paro por debajo del 10\% y el PIB español por encima del $90 \%$ de la media comunitaria de la Europa de los 15, y casi en el 100\% de la media de la Unión Europea de los 25. España disponía, en 1985, de 2.117 kilómetros de autopistas y autovías, hoy tiene 13.000 kilómetros. De la mano de nuestra entrada en la UE vino la apertura definitiva de nuestra economía y una mayor presencia en la escena internacional. (Piedrafita, Steinberg y Torreblanca, 2006).

Los niveles a los que hace referencia dicho estudio y que contemplan incrementos en positivo son entre otros; el crecimiento y la riqueza, la convergencia en renta con respecto al resto de socios europeos, $\mathrm{El}$ acusado descenso de los niveles de desempleo, la afluencia de inversiones exteriores, la bajada de los tipos de interés, la regulación fiscal común, el incremento del turismo y la calidad de vida de la población, la tasa de actividad y ocupación, el reforzamiento y avance en materia de educación, derechos sociales y la cultura política.

En este contexto es en el que se generó la burbuja inmobiliaria en España. Con esto no pretendemos afirmar que lo explicado anteriormente sea la causa única y esencial, sin duda, las causas han de buscarse en una confluencia de factores y decisiones que han de estudiarse desde una perspectiva multidisciplinar como venimos proponiendo. Análisis desde ámbitos concretos son muchos y de diversas características, lo que nosotros proponemos es un análisis desde la perspectiva del discurso publicitario. A modo de ejemplo y desde el punto de vista económico, (Bernardos Domínguez, 2009) ofrece el dibujo del panorama concreto que dio lugar a la creación de la burbuja.

El autor señala como principales causas desde la imposibilidad de ofrecer una política monetaria propia, lo que desembocó en una bajada precipitada de los tipos de interés y por tanto una oleada especulativa, a la inacción de los diferentes gobiernos de la época, la excesiva competencia bancaria que provocó la asunción de demasiados riesgos y la excesiva oferta de viviendas que no se correspondía en absoluto con unos niveles de demanda reales.

Años después del estallido de la burbuja inmobiliaria, siguen publicándose informes y estudios relativos al tema. Quizá la razón de esta persistencia hay que buscarla en la incertidumbre presente acerca de las consecuencias que aún quedan por resolver, la incidencia de la crisis económica en gran parte de los países industrializados motiva que el tema siga aún vigente y la búsqueda de indicadores y explicaciones en todos los ámbitos está a la orden del día.

Un estudio publicado en noviembre de 2012 por el Banco de España sobre el impacto de la crisis económica en la industria española, pone de manifiesto una vez más que, si bien es cierto que la crisis viene provocando grandes retrocesos en la producción 
industrial en toda la zona del euro, el impacto en España es aún más acusado, no apreciándose atisbos de recuperación hasta bien entrado el año 2009.

Las industrias relacionadas con la actividad de la construcción suponían en torno a 2005, algo más de un 21 \% de la producción industrial en España, porcentaje superior al registrado en países como Alemania (18\%) o Francia (12\%). En base al índice compuesto de las industrias de la construcción en el período 2007-2012, en España existe en 2012 un 55\% menos de producción de este tipo con respecto a 2007.

La consecución de un período de estabilidad política y social, el asentamiento de un régimen democrático y la paz institucional en nuestro país, afianzó de forma definitiva las bases sobre las que se desenvolvería el crecimiento estructural.

Analizar la deriva del sistema capitalista es hablar indefectiblemente de la crisis económica actual pero también, por su relación con nuestro objeto de estudio, es hablar del consumo, el que parece factor más definitorio de la cultura contemporánea o posmodernidad.

En el momento de redactar estas palabras, principios de 2012, han transcurrido cinco años desde el estallido de lo que ha venido a llamarse, la mayor crisis financiera de occidente desde el crack de 1929. Hoy, el panorama en un gran número de potencias europeas no es muy distinto del que se hacía presagiar tras la quiebra de importantes instituciones financieras como el banco de inversión estadounidense Lehman Brothers que se declaró en bancarrota el 15 de septiembre de 2007 o su rival Merrill Lynch que fue vendido con carácter de urgencia al Bank of América por 50.000 millones de dólares poco después. Antes, durante y después de este fatídico mes ya se venían produciendo continuos derrumbes en las principales bolsas del llamado primer mundo. Las grandes corporaciones financieras debieron ser inyectadas fulgurantemente por bancos y reservas estatales con una liquidez que paliaría un mal que hoy se nos muestra como endémico.

Sea como fuere, el mundo parece vivir hoy endeudado, rescatado, hipotecado, deprimido y hastiado. Cansado de consumir, arrepentido y temeroso, el mismo primer mundo que hasta hace bien poco se jactaba de su poder omnímodo, sobrevive entre rescates, ayudas, prestaciones y miedo a un futuro incierto. En una sociedad sobreinformada como la actual, curiosamente suscita más interés y genera mayor controversia la búsqueda de la causa, el desencadenante o chispa que encendió la llama de la depresión, que las posibles salidas razonables y razonadas. Quizá porque no seamos capaces de imaginarlo o porque el propio sistema se encargó de aniquilar cualquier alternativa para convertirse en la única y verdadera opción, ahora parece no haber salida.

La información, la literatura y el conocimiento que se está generando hoy en día en torno a las posibles claves explicativas de la precaria situación actual del primer mundo, proviene de todos los ámbitos, la sociología, la psicología, la filosofía, la política, las ciencias económicas y empresariales, las ciencias de la comunicación, la antropología, la futurología y hasta la astrología, dedican ingentes cantidades de 
materia gris para dilucidar las claves de un fracaso casi global. Conscientes de nuestra innata capacidad para tropezar dos veces en la misma piedra, tratamos de enumerar nuestros pecados capitalistas y purgarlos con la promesa de no volver a caer.

En nuestro caso, centraremos el interés en dos ámbitos que a nuestro juicio se hayan más relacionados con la temática que nos ocupa, sin menospreciar en ningún momento otras visiones, decidimos centrar nuestra atención en la perspectiva ofrecida por economistas y sociólogos. En este sentido no es nuestra intención ofrecer una panorámica del pensamiento global sino un acercamiento a las teorías más próximas al objeto de estudio. A grandes rasgos podríamos diferenciar dos corrientes de pensamiento diferenciadas; aquellas que invocan a una crisis sistémica universal cuyo origen se encontraría en la propia corrosión del sistema y otras que desde un punto de vista más reduccionista achacan el estado depresivo de la sociedad contemporánea a una serie de errores cometidos en el ámbito del sistema financiero internacional cuyo epicentro se encontraría en el mercado inmobiliario principalmente como factor de distorsión de la economía y las finanzas globales. Esta distinción ya fue descrita por (Morin, Altvater, Amin y Gowan, 2010) quienes afirman un error cualquier extremo, desde la interpretación minimalista de aquellos que reducen el problema a la crisis financiera de las hipotecas subprime, a el otro extremo que ve en la crisis la materialización de otra crisis aun mayor; la del capitalismo.

La cultura de consumo, insertada en las sociedades industrializadas, facilita y alimenta el movimiento de estas en torno a un rumbo posmoderno que necesita para su existencia y perpetuación del consumo. Consumo constante y fluido de mercancías significantes que además configuran el estilo de los grupos, las ciudades, los países y el mundo. En un tono radical, el consumo es el sistema y el sistema es el consumo, el modelo capitalista se retroalimenta así de una incesante obsolescencia planeada de nuestros gustos, experiencias, placeres y emociones. El consumo conspicuo, del que ya se tienen noticias desde que Thorstein Veblen a finales del siglo XIX caracterizase los hábitos comunes de una clase ociosa proliferante, define con una nitidez premonitoria, el devenir de una sociedad entregada a la distinción de la que más tarde hablara (Bourdieu, 2003) y que hoy, más de un siglo después, sigue apoyándose indefectiblemente, como aquel entonces, en una industria comunicativa transmisora de estilos y modas. En la sociedad que describe (Veblen, 2002), el consumo era un medio de conseguir reputación y decoro.

Si este hecho tenia mayor influencia en aquellas comunidades donde el contacto humano y la movilidad de sus integrantes era mayor, no parece descabellado pensar que hoy, gracias a las tecnologías de la comunicación, las redes sociales y la incesante movilidad de la población, el fenómeno se amplíe exponencialmente. La delgada línea que separa el consumo necesario y vital del derroche -que sigue llevando consigo un tono peyorativo- es aún más difusa si cabe gracias a la superproducción y al imaginario expelido por la publicidad. El espacio-tiempo que separa la percepción de un objeto como derroche a convertirse en un objeto necesario para la vida, es tan ínfimo que a veces antecede a la propia aparición del objeto en el mercado. 
Los amantes del gadget, el último y definitivo adelanto, esperan pacientes a la entrada del megastore para encontrarse con una vida mejor, más cómoda, más domótica y conectada. Porque ahora la mercancía que les distingue no sólo tiene fecha de defunción, ahora además tiene día y hora de nacimiento. Una fecha inteligentemente marcada en el calendario para que se asegure el correcto reciclaje social y emocional, para que los deseos y las aspiraciones se renueven y ventilen en el momento exacto y no perdamos el hilo, no nos desviemos un ápice del camino marcado, del sistema pensado y trazado para nuestra felicidad y su supervivencia por los años de los años. Si como afirma (Hellín Ortuño, 2007); "el consumismo es probablemente la característica diferencial, más destacable de la posmodernidad". Este consumo se manifiesta desde el plano simbólico para representar una estructura social a través de los objetos que se ponen a nuestra disposición para que podamos exhibirlos y exhibirnos. Integrador y simbólico como afirma Hellín Ortuño citando a González Martín, "el consumo se presenta entonces como la única alternativa para el sistema total" (Op. Cit. 2007, p. 71) y genera por sí mismo una serie de conductas definitorias del estado de las sociedades en la posmodernidad. En este contexto, las consecuencias a grandes rasgos van desde la utilización de los sujetos como instrumentos de consumo, el individualismo, la mercantilización de la vida cotidiana, la propagación del goce inmediato para cambiar y renovarnos constantemente, hasta la orientación total y definitiva de la sociedad hacia el consumo, el consumo es el sistema.

Hablar de consumo simbólico en un estudio acerca de la publicidad en el sector inmobiliario nos remite directamente a las investigaciones de (Bourdieu, 2003) en torno al mercado de la casa como parte esencial de una inmersión de la economía en lo social. La vivienda, como un producto más, posee un componente simbólico especialmente relevante, como bien material, es susceptible de exposición y percepción por los otros a la vez que de manera duradera delata el ser social del propietario, sus gustos y sus posición concreta en el espacio social. Es además, como manifiesta el autor, un producto con connotaciones afectivas y económicas importantes ya que supone una de las mayores inversiones, si no la mayor, que puede realizarse hoy en día. Conlleva unas consecuencias para el comprador y su entorno familiar y/o afectivo que van más allá del aspecto económico para convertirse en un bien patrimonial y transmisible que en la mayoría de ocasiones sobrevive al propio comprador.

Este punto de partida parece hoy irrefutable, hasta el punto de que, como señalábamos anteriormente el mercado de la vivienda posee un papel preponderante en el devenir de la economía en las sociedades industrializadas debido a la formación de burbujas y a la cadena de actos financieros que desencadena a nivel global. La puesta en circulación y el consumo de productos financieros asociados directamente al mercado inmobiliario son señalados casi por unanimidad como germen de la crisis y el estado de las sociedades occidentales desde 2008. Un consumo que guarda poco de aquel cuyo objetivo era la satisfacción de una necesidad primaria, como es la disposición de un lugar en el que vivir, para convertirse en un acto simbólico, que representa una serie de aspiraciones emocionales con vistas a obtener una ubicación idónea y ansiada del comprador en el escenario social compartido. Una inversión distintiva, personal y transferible. 
Aceptando estas premisas, ya expuestas por Bourdieu como decimos, no podemos obviar la contribución que los diferentes agentes intervinientes en el mercado inmobiliario, realizan sobre el acto de consumo. De esta forma el Estado también contribuye a la formación de la demanda a través de disposiciones en un sentido o en otro, bien sea mediante la inyección de recursos al sistema en forma de ayudas o a través de reglamentaciones que hacen variar el rumbo y las condiciones de acceso a la vivienda; los tipos de interés, las deducciones fiscales, el fomento del alquiler, la disposición de normativas que regulan el suelo y otras.

Si el Estado ejerce una influencia innegable en el mercado de consumo inmobiliario, la publicidad también contribuye decisivamente en la formación y estructura del mercado y la demanda. También descrito por Bourdieu en esta misma obra:

La publicidad moviliza palabras o imágenes capaces de hacer resurgir las experiencias asociadas a la casa, de las que podemos decir, sin contradecirnos, que son comunes y singulares, triviales y únicas" (Op. Cit. 2003, p. 38).

Como agente esencial del mercado inmobiliario, la publicidad evoca nuestras disposiciones ya existentes para aprovecharlas de forma más óptima y hacernos sentir que alguien se preocupa y sirve a nuestros deseos, exigencias y gustos.

Las sinergias que se están generando en las últimas décadas entre arquitectura y turismo, han convertido a España nuevamente, en un terreno abonado para el desarrollo de un fenómeno relativamente nuevo. Si el país ya poseía una oferta casi inigualable en lo que se refiere a patrimonio histórico, durante las últimas décadas el paquete de propuestas se ha visto incrementado exponencialmente con una nueva remesa de edificios, museos, puentes colgantes, auditorios y ciudades temáticas, a menudo firmados por arquitectos de prestigio y siempre financiados con el erario público que trataban de atraer la mirada del turismo internacional al albor de una supuesta regeneración territorial y activación del tejido industrial y de servicios.

La construcción para el turismo de masas, los edificios con firma, la ciudad de autor han elevado a la disciplina arquitectónica en general y a los arquitectos en particular a un estatus tan elevado que su presencia o rúbrica en cualquier proyecto es capaz de despertar la máxima generosidad de los contratantes. Si además, la factura corre a cargo de la ciudadanía, el ritmo se acelera y la satisfacción es doble. El museo Guggenheim de Bilbao, la Ciudad de las Artes y las Ciencias de Valencia, arquitectos como Rafael Moneo o Santiago Calatrava, han sembrado el país de aeropuertos, rascacielos, centros de congresos, instalaciones deportivas, auditorios, museos y hasta bodegas. Todo ello parece haber eclipsado al turismo tradicional como así lo demostraba la exposición que pudo verse en el Moma de Nueva York en febrero de 2006. En ella se ponía de relieve la concentración de edificios singulares emblemáticos en España. Fruto de los fondos provenientes de los socios europeos, en pro de una supuesta regeneración estructural necesaria, las aspiraciones de gobernantes locales y nacionales habían entrado en una carrera inversionista de peligrosas consecuencias, pues la amortización de estas costosas obras, como estamos viendo no resulta fácil. 
Aunque nuestro objeto de estudio poco tiene que ver con esta corriente de arquitectura de masas, creemos que si es obligada la referencia pues supone la aceptación de la arquitectura como un fenómeno de consumo, un consumo sígnico como afirma (Baudrillard, 2010) que da sentido y pertenencia a los objetos (ciudades) en la vida de las personas. Un consumo contemporáneo basado en la experiencia. "Así como el proyecto del postmodernismo es el reencantamiento del mundo, el proyecto de la ciudad nueva contemporánea se convierte en el reencantamiento de la experiencia urbana". (Amendola, 2000, p. 60). Una experiencia hedonista en la que reina la razón estética y la capacidad de transformar la vida del que la atraviesa, experiencias gastronómicas, culturales, paisajísticas, místicas, históricas, etc.

Otro gran foco de atención sobre el que centraremos nuestra mirada en la presente investigación, lo constituye el pensamiento proveniente de la sociología de la posmodernidad. Como dijimos anteriormente, la presente tesis está enfocada en torno a un eje espacio/tiempo muy concreto. Por este motivo decidimos apoyarnos en la teoría y práctica surgida en torno a los aspectos sociales y culturales imperantes, lo que la comunidad científica ha venido a denominar posmodernidad. La publicidad como fenómeno económico que afecta a lo social y el desorbitado impulso de la industria inmobiliaria, ambas constituyen rasgos identitarios de la cultura y sociedad contemporánea. La condición postmoderna, desde sus actas fundacionales en (Lyotard, 2008), hasta la liquidez de (Bauman, 2009), pasando por el consumo, el hiperindividualismo, la cultura de masas, el hedonismo y lo efímero en (Lipovetsky, 1990). Aquel mapa del cuento de Borges que interpretado por (Baudrillard, 1993), no era más que una sucesión de simulacros que suplantaban a la realidad, con el mapa de nuestras ciudades y pueblos inmersos en la vorágine inmobiliaria, donde la publicidad inmobiliaria campaba a sus anchas en una suerte de burbuja que suplantaba el desarrollo y crecimiento y que definitivamente explotó.

Las industrias de la comunicación de la mano del crecimiento y el desarrollo social y cultural también encontrarán en estos años el terreno abonado sobre el que consolidar su expansión y crecimiento.

El bloque analítico de esta lo constituirá un estudio de los mensajes, el discurso vertido por la industria inmobiliaria. Si la semiótica nos ayudará a conformar un esquema metodológico propio y apropiado, las teorías de la comunicación y los estudios procedentes sobre comunicación publicitaria, sus técnicas, soportes y agentes, harán el resto. Hablamos de todas aquellas contribuciones en torno a la creatividad publicitaria, en las formas y contenidos, desde el discurso y sus esquemas, hasta los mismos formatos y medios de difusión, desde su lenguaje hasta sus efectos. Comprender el funcionamiento, profundizar en los procesos creativos, la estrategia, la creación y la difusión.

La obra inicial de (Barthes,1990) y los conceptos para el análisis semiológico, así como el posterior camino desarrollado por la semiótica y más concretamente, el análisis del discurso publicitario a través de esta. $($ Eco,1999) y sus indagaciones sobre la semiótica de los mensajes visuales, insistiendo más que en el desvelamiento de la operación ideológica burguesa, en la naturaleza consolatoria de la publicidad desde el punto de vista retórico y estético. Hablar de semiótica en Europa es hablar de la corriente de los Estudios Culturales, la Escuela de Fráncfort, donde destacamos la mirada sobre las 
culturas populares de (García Canclini,1995), la sociología urbana de (Maffesoli, 1990), los medios y la sociedad en (Martín Barbero,1998) o (Bourdieu, 2003), las relaciones entre los códigos y el poder en Foucault (1999), la ideología, la comunicación y la cultura con (Hall, 1996) y la posmodernidad en el capitalismo avanzado por (Jameson, 2008). La mirada semiótica, en palabras de (Paolo Fabri, 2000) y su genuina tridimensionalidad sintáctica, semántica y pragmática. En este sentido es importante la contribución de la obra de (Rodríguez y Mora, 2002), desde la Universidad de Alicante, en torno a la comprensión y análisis global y certero de la comunicación publicitaria a través de la mirada semiótica.

\section{DISCUSIÓN}

Una vez demostrada la necesidad de investigar los mecanismos discursivos de la publicidad inmobiliaria por estar relacionados con un sector relevante de cara al devenir socio económico y político de las sociedades industrializadas, queda demostrado que:

El estudio de la publicidad, como herramienta de representación social, captadora y transmisora de valores imperantes y componente esencial en la estructura de una sociedad orientada voluntariamente hacia el consumo, puede inferir características y peculiaridades del contexto en el que se desenvuelve. Podemos seguir el rastro de determinados fenómenos sociales o culturales a través del análisis de los mecanismos discursivos de la publicidad. La publicidad hoy es un marco de referencia social, ideológico y cultural, un espejo en el que se reflejan las sociedades industrializadas, inmersas desde hace décadas en la vorágine del consumo que el sistema capitalista produce y reproduce de forma ininterrumpida. El consumo es la característica esencial de la cultura posmoderna, la publicidad como exégeta, alumna aventajada, fiel servidora, dramaturga y portavoz leal, anima y remueve continuamente el espíritu consumista de una sociedad con un presente líquido, un futuro incierto y un pasado aún en gran medida por desvelar. Es precisamente aquí donde reside el sentido de nuestra investigación

España constituye un caso paradigmático de estudio en lo que se refiere a impacto económico y social de la burbuja inmobiliaria. Los cambios políticos, económicos, sociales y culturales acaecidos en este país en los últimos años del siglo XX y principios del XXI, constituyen una referencia para el estudio de este fenómeno. Las consecuencias del llamado boom del ladrillo aún resuenan en la mente de economistas, políticos, sociólogos, banqueros, periodistas, historiadores y prácticamente cualquier persona, pues la crisis económica propiciada en buena medida -no exclusivamente- por aquella, alcanza a todos. Un análisis diacrónico, explorativo y descriptivo del contexto histórico resulta esencial para comprender las circunstancias que rodean el fenómeno.

España no solo es un ejemplo de construcción residencial más o menos desorbitada, de igual forma la construcción de autor, como explicamos más arriba, aquella que de la mano de arquitectos de renombre, es usada con fines turísticos o de masas, encontró en España un escenario de primera categoría. De la mano de gobernantes y en pro de 
una europeización pendiente, la arquitectura se ha convertido aquí también en un producto susceptible de generar contenidos lo suficientemente relevantes como para variar la fisonomía de las ciudades y la percepción de las mismas, su lugar en el mundo, su distinción y valor.

Las conclusiones de este artículo son una batería de preguntas a las que nos proponemos dar contestación mediante el estudio que aquí presentamos. Hacemos pública la necesidad de abrir un debate en torno al fenómeno estudiado. Así a través del estudio del discurso o los discursos en los materiales analizados, podríamos hallar respuestas sobre el papel que desempeñó la publicidad en la formación y mantenimiento de la burbuja, qué conceptos, valores o estilos de vida se transmitían, a quien, en qué momento y con qué medios, su capacidad de transmisión ideológica, la propia conformación de gustos, o la creación de estándares de identidad.

De este modo y mediante la publicidad como mediadora de representaciones y reveladora de aspectos sociales podremos inferir las características y peculiaridades de un período histórico relativamente corto pero de gran trascendencia como podemos comprobar hoy.

\section{REFERENCIAS}

Alves Dias, M. (2009). Construções retóricas do discurso publicitário de condominios residenciais. Tesis de maestría. Escola Superior de Propaganda e Marketing. ESPM, São Paulo.

- (2009). Publicidade Imobiliária e suas construçoes retoricas. XXXXII Congreso Brasileiro de Ciencias de Comunicação. 4-7 de septiembre, Curitiba.

- (2008). Publicidade Imobiliária e a Construção de Lugares Simbólicos como extensão de identidades. XXXXII Congreso de Ciencias da Comunicação na Regiao Sudeste. 710 de mayo, Sao Paulo.

Amendola, G. (2000). La ciudad posmoderna. Magia y miedo de la metrópolis contemporanea. Madrid: Celeste.

Barthes, R. (1990). La Aventura semiológica. Barcelona: Paidós.

Baudrillard, J. (2010). El sistema de los objetos. Madrid: Siglo XXI.

- (1993). Cultura y simulacro. Barcelona: Kairós.

Bauman, Z. (2009). Tiempos líquidos. Vivir en una época de incertidumbre. Barcelona: Tusquets.

Bernardos Domínguez, G. (2009). Creación y destrucción de la burbuja inmobiliaria en España. Información Comercial Española, ICE: Revista de economía, 850, p. 23-40.

Bourdieu, P. (2003). Las estructuras sociales de la economía. Barcelona: Anagrama. 
Codeluppi, V. (2007). El papel social de la publicidad. Pensar la publicidad, revista internacional de investigaciones publicitarias, 1(1), 149-157.

Eco, U. (1999). La estructura ausente. Barcelona: Lumen.

Fabbri, P. (2000). El Giro Semiótico. Barcelona: Gedisa.

Foucault, M. (1999). Estrategias de poder. Barcelona: Paidós.

García Canclini, N. (1995). Consumidores y ciudadanos. México, D.F.: Grijalbo.

Hall, S. (1996). Critical dialogues in cultural studies. London: Routledge.

Hélio Junqueira, A. (2010). Construções retóricas na publicidade imobiliária brasileira contemporânea: encantamento e cinismo frente às aspirações do morar bem. V ENEC, Encontro Nacional de Estudos do Consumo. I Encontro Luso-Brasileiro de Estudos do Consumo Tendências e ideologias do consumo no mundo contemporáneo. 15, 16-17 de septiembre, Rio de Janeiro.

Hellín Ortuño, P. A. (2007). Publicidad y valores posmodernos. Madrid: Siranda.

Jameson, F. (2008). El posmodernismo o la lógica cultural del capitalismo avanzado. Barcelona: Paidós.

Lipovetsky, G. (1990). El imperio de lo efímero. La moda y su destino en las sociedades modernas. Barcelona: Anagrama.

Lyotard, J.F. (2008). La condición postmoderna. Madrid: Cátedra.

Maffesoli, M. (1990). El tiempo de las tribus: el declive del individualismo en las sociedades de masas. Barcelona: Ikaria.

Martín Barbero, J. (1998). Cultura, medios y sociedad. Universidad Nacional de Colombia, Facultad de Ciencias, Centro de Estudios Sociales. Disponible en: http:// www.bdigital.unal.edu.co/1272/2/01PREL01.pdf

Martínez Velencoso, L.M. (2008). Cuestiones económicas en torno a las reglas de transmisión de la propiedad y de publicidad inmobiliaria. InDret, 4. Disponible en: http:/ / www.indret.com/es/index.php

Piedrafita, S., Steinberg, F. y Torreblanca, J.I. (2006). 20 años de España en la Unión Europea (1986-2006). Madrid: Real Instituto Elcano.

Renno, R. (2003). A cidade das marcas - Marcas na cidade. XXVI Congresso Anual em Ciência da Comunicação. 2-6 de septiembre, Belo Horizonte.

Rodrigo Alsina, M. (1989). Los modelos de la comunicación. Madrid: Tecnos. 
Roubini, N. y Mihm, S. (2010). Cómo salimos de ésta. Barcelona: Destino.

Soros, G. (2008). El nuevo paradigma de los mercados financieros. Para entender la crisis económica actual. México, D.F.: Taurus.

Serna Vallejo, M. (1995). La publicidad inmobiliaria en el derecho hipotecario histórico español. Doctorado, Universidad de Cantabria, Santander, España.

Tusell, J. (2002). La alternativa de la derecha (1996-2000). Actas del III Simposio de Historia Actual, Carlos Navajas Zubeldía, coord. 26-28 de octubre, Logroño, p. 177194.

Veblen, T. (2002). Teoría de la clase ociosa. Madrid: Fondo de cultura económica de España.

Verón, E. (1987). La semiosis social: fragmentos de una teoría de la discursividad. Barcelona: Gedisa. 


\section{Antonio Raúl Fernández Rincón}

Licenciado en Publicidad y Relaciones Públicas por la Universidad Complutense de Madrid (1995). En estos momentos se encuentra realizando la tesis doctoral "Los mecanismos discursivos de la publicidad inmobiliaria", junto al Prof. Dr. Pedro A. Hellín Ortuño, Universidad de Murcia. Ha desarrollado su carrera alternando labores profesionales en diversas agencias de publicidad con la formación académica, llegando a obtener en 2010 el título de Máster en Estudios Avanzados en Comunicación por la Universidad de Murcia. En la actualidad es profesor asociado de la Facultad de Comunicación y Documentación de la Universidad de Murcia. 